\title{
Benefits of superfine grinding method on antioxidant and antifungal characteristic of
}

\section{Brazilian green propolis extract}

\author{
Thalita Riquelme Augusto-Obara ${ }^{1} \odot$, Jacqueline de Oliveira ${ }^{\oplus}$, Eduardo Micotti da Gloria ${ }^{1}$, Marta Helena Fillet Spoto ${ }^{1}$, Karina \\ Godoy $^{2} \odot$, Thais Maria Ferreira de Souza Vieira ${ }^{1 \oplus}$, Erick Scheuermann²*৫
}

'Universidade de São Paulo/ESALQ - Depto. de Agroindústria, Alimentos e Nutrição, Av. Pádua Dias, 11 13418-900 - Piracicaba, SP - Brasil.

2Universidad de La Frontera - Depto. de Ingeniería Química y Núcleo de Desarrollo Científico Tecnológico - Bioren, Av. Francisco Salazar, 1145 - 4811230 - Temuco - Chile.

*Corresponding author <ericks@ufrontera.cl>

Edited by: Luís Guilherme de Lima Ferreira Guido

Received February 26, 2018

Accepted May 03, 2018
ABSTRACT: Green propolis is found only in Brazil and due to its important biological characteristics, the food industry views it as a rich source of bioactive compounds. However, an extract must be produced for its application, which is difficult considering the rigid characteristics of raw propolis. Superfine grinding, a process capable of reducing particle size, enables the extraction of most bioactive compounds in propolis. This study evaluated the influence of grinding on size characteristics, antioxidant and antifungal properties of Brazilian green propolis for food preservation. The propolis powder was produced through six different types of grinding (different sieves and $\mathrm{rpm}$ ), and its quality was evaluated by scanning electron microscopy-energy dispersive X-ray spectroscopy. After grinding, extracts and bioactive assays were produced and the total phenolic content, antioxidant and antifungal capacity were determined. The data showed that the grinding process affected all the results of bioactive assays used. Treatment B (sieve $0.08 \mathrm{~mm}, 12,000 \mathrm{rpm}$ ) presented statistically significant values for the bioactivity assays and thus antifungal activity against Rhizopus stolonifer (doses 0-5\%) was tested only for the control (standardized size without superfine grinding) and treatment B. Both treatments showed antifungal activity, but the control provided more effective mycelial growth inhibition (lower dose $1 \%$ ). Superfine grinding increased the antioxidant activity, although this behavior was not observed in the antifungal assay. Despite these results, green propolis extracts present important biological effects that indicate their use as food preservatives to extend shelf life of food products.

Keywords: Apis mellifera, SEM-EDX, ultracentrifugal mill, total phenolic content, food preservative

\section{Introduction}

Propolis is a resinous material produced by bees using vegetable resins, exudates and pollen collected from plants and combining them with self-secretions. The main chemical components in propolis are resin, wax and essential oils (Viuda-Martos et al., 2008). Several health benefits of propolis have been reported (Fernandes-Silva et al., 2014; Ribeiro et al., 2015; Wang et al., 2016), as well as its application to foods, beverages, cosmetics and medicine (Chinembiri et al., 2014; Cottica et al., 2015; Bruschi et al., 2016; Osés et al., 2016). Brazilian green propolis is a type of propolis that can be found only in Brazil (São Paulo and Minas Gerais States) and is produced by Africanized Apis mellifera bees via collection of Baccharis dracunculifolia DC (Asteraceae) shoots (Alencar et al., 2005). Many compounds in plant composition can also be found in green propolis, such as artepillin $\mathrm{C}$, flavonoids and p-coumaric acid, which are associated with its antioxidant capacity (Guimarães et al., 2012). Additionally, flavonoids and phenolic acids in green propolis have antifungal activities for typical agricultural, food, medical and odontological fungi (Ngatu et al., 2011; Freires et al., 2016; Martini et al., 2017). However, propolis is a tough resin that cannot be consumed in its natural form; thus, resin is typically transformed into a powder and extracted in an alcoholic or aqueous medium (Mello and Hubinger, 2012). Process conditions are important to allow extraction of most bioactive compounds. The efficiency of the solid/liquid extraction depends on processing parameters, such as temperature, solvent, extraction duration and particle size (Franco et al., 2007).

Given particle size importance, superfine grinding technology has emerged to enhance characteristics that the raw material does not possess, such as solubility, dispersion, optical properties, surface effects and chemical reactivity (Wu et al., 2012). Enhancement is favored by the smaller particle size and higher extraction temperature, which generally facilitate mass transfer (Cacaeo and Mazza, 2003), enabling the production of extracts with a higher amount of bioactive compounds (Rosa et al., 2013). In addition, superfine grinding consumes less energy than traditional mechanical grinding (Wu et al., 2012). Therefore, the objective of this study was to evaluate the influence of grinding on the size characteristics, antioxidant and antifungal properties of Brazilian green propolis compared with those in their raw condition, aimed at using extracts for food preservation.

\section{Materials and Methods}

The experiments were carried out in Temuco $\left(38^{\circ} 45^{\prime} 00^{\prime \prime} \mathrm{S} ; 72^{\circ} 40^{\prime} 00^{\prime \prime} \mathrm{W}\right)$ and altitude 360 a.s.l., Chile and Piracicaba $\left(22^{\circ} 43^{\prime} 31^{\prime \prime}\right.$ S; $47^{\circ} 38^{\prime} 57^{\prime \prime}$ W) and altitude 547 a.s.l.), São Paulo, Brazil. 


\section{Propolis material, superfine grinding method and extract preparation}

The green propolis was obtained from a Brazilian specialized company and was collected on 16 Apr., 2015,

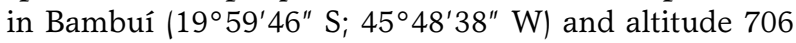
a.s.l., Minas Gerais, Brazil. Initially, the green propolis particles were standardized with diameters from $5 \mathrm{~mm}$ to $1 \mathrm{~mm}$ (control). The uniform coarse particles were ground in an ultracentrifugal mill using mesh sieves with different diameters $(0.08 \mathrm{~mm}$ and $0.5 \mathrm{~mm})$ using different rotational speeds $(6000,12,000$ and 18,000 $\mathrm{rpm})$. The standardized propolis was used as the control sample, and six different methods of grinding with different rotational speeds and sieve sizes were tested. The treatments were designated as follows: A: sieve $0.08 \mathrm{~mm}$ $\varnothing$ at $6000 \mathrm{rpm}$; B: sieve $0.08 \mathrm{~mm} \varnothing$ at $12,000 \mathrm{rpm}$; C: sieve $0.08 \mathrm{~mm} \varnothing$ at $18,000 \mathrm{rpm}$; D: sieve $0.5 \mathrm{~mm} \varnothing$ at $6000 \mathrm{rpm}$; E: sieve $0.5 \mathrm{~mm} \varnothing$ at $12,000 \mathrm{rpm}$; and F: sieve $0.5 \mathrm{~mm} \varnothing$ at $18,000 \mathrm{rpm}$.

To prepare the extracts, 2 g of propolis was weighed, ground and transferred to an Erlenmeyer flask containing $25 \mathrm{~mL}$ of solvent (ethanol: water, 7:3, $\mathrm{v} \mathrm{v}^{-1}$ ). After the grinding process, performed as described above, extraction was performed at $45{ }^{\circ} \mathrm{C}$ for $20 \mathrm{~min}$ with constant shaking in a water bath. Next, the solution was placed in a freezer at $-22{ }^{\circ} \mathrm{C}$ overnight, centrifuged at $5000 \mathrm{rpm}$ for $10 \mathrm{~min}$ for wax removal, filtered using Whatman No. 2 paper filters, and kept in an amber flask until analysis. For the antifungal analysis, the extract was evaporated using a rotavapor until ethanol was completely removed.

\section{Particle size measurement and mass percent determined via scanning electron microscopy- energy dispersive $\mathrm{X}$-ray spectroscopy (SEM-EDX)}

The ground samples were prepared in situ and joined with carbon double-sided tape. Then, the samples were examined using a variable pressure-SEM (VP-SEM) with energy of $5 \mathrm{kV}$, working distance of 11 $\mathrm{mm}$, backscatter compositional detector (BSE), 100-270, magnification of 500x, and $20 \mathrm{~Pa}$ on a scanning electron microscope. An SEM-EDX semiquantitative elemental microanalysis was performed using energy of $10 \mathrm{kV}$, working distance of $11 \mathrm{~mm}$, pressure of $20 \mathrm{~Pa}$, and magnification of 500x, and the EDX Brüker was attached to a scanning electron microscope.

\section{Total phenolic content (TPC)}

The TPC of propolis extracts was determined according to Singleton et al. (1999) using gallic acid as a standard. The hydroalcoholic extracts were diluted in a mixture of ethanol and water $(1: 10, v / v)$. A $0.5 \mathrm{~mL}$ aliquot of diluted sample was transferred to a test tube, then, $2.5 \mathrm{~mL}$ of a Folin-Ciocalteau: water solution (1:10, $\mathrm{v} / \mathrm{v}$ ) was added. The mixture was vortexed and then allowed to rest at room temperature for $5 \mathrm{~min}$. Next, 2.0 $\mathrm{mL}$ of a sodium carbonate $(4 \%, \mathrm{~m} / \mathrm{v})$ solution was added then the mixture was vortexed, allowed to rest for $2 \mathrm{~h}$ at room temperature and protected from light. Absorbance of samples was read at $740 \mathrm{~nm}$ using a UV spectrophotometer. The results were calculated using a standard curve for known concentrations of gallic acid (2.5 to 50 $\left.\mu \mathrm{g} \mathrm{mL}^{-1}\right)$, and the results are expressed as $\mathrm{mg}$ of gallic acid equivalent (GAE) $\mathrm{g}^{-1}$ of propolis.

\section{ABTS radical cation scavenging}

The ABTS [2,2'-azinobis-(3-ethylbenzothiazoline6-sulfonic acid)] assay was used to determine the antioxidant activity using the method described by Re et al. (1999). The ABTS radical was formed via the reaction between $7 \mathrm{mM} \mathrm{ABTS} \cdot+$ solution and $140 \mathrm{mM}$ potassium persulfate solution. The solutions were incubated at $25{ }^{\circ} \mathrm{C}$ in the dark for $12-16 \mathrm{~h}$. Once the radical was formed, it was diluted with analytical grade ethanol until an absorptivity value of $0.700 \pm 0.020$ was reached at $734 \mathrm{~nm}$. Dilutions of the extracts were prepared, and a $30 \mathrm{~mL}$ aliquot of each extract dilution was transferred to a test tube with $3.0 \mathrm{~mL}$ of the ABTS radical. The absorbance was determined at $734 \mathrm{~nm}$ after $6 \mathrm{~min}$ of reaction using a spectrophotometer. Trolox was used as a standard, and the results were expressed as $\mu \mathrm{mol}$ Troloxequivalent antioxidant capacity (TEAC) $\mathrm{g}^{-1}$ of propolis.

\section{Free radical scavenging activity with DPPH}

The antioxidant activity was also determined using the DPPH (2,2-diphenyl-1-picrylhydrazyl) radical method described by Brand-Williams et al. (1995). A solution containing $0.5 \mathrm{~mL}$ of diluted extract, $3.0 \mathrm{~mL}$ of $99 \%$ ethanol, and $0.3 \mathrm{~mL}$ of a $0.5 \mathrm{mM} \mathrm{DPPH}$ radical solution was added to a test tube. A blank sample was prepared by replacing the extract volume for an equal volume of $99 \%$ ethanol. The tubes were shaken and incubated for $45 \mathrm{~min}$ at room temperature and protected from light. The absorptivity readings were performed using a spectrophotometer at $515 \mathrm{~nm}$. The antioxidant activity results were expressed as $\mu \mathrm{mol}$ TEAC g ${ }^{-1}$ of propolis. Trolox $(0.1 \mu \mathrm{mol})$ was used as a standard to construct the calibration curve.

\section{Antifungal activity}

The antifungal activity was tested against Rhizopus stolonifer. The agar dilution method was performed according to Alvarez-Castellanos et al. (2001). The development inhibition was measured for different extract concentrations dissolved in Plate Dextrose Agar (the substrate for fungus development). The $R$. stolonifer inoculums were obtained via direct isolation from strawberries with lesions characteristic of the disease. To identify the species, molecular tools, such as the polymerase chain reaction and genes, were used (Vilgalys and Hester, 1990). For R. stolonifer inoculation, a metal rod was used to punch the agar after it was immersed in a suspension of inoculum containing $10^{5}$ spores $\mathrm{mL}^{-1}$. The inoculums were prepared from fungal colonies that were grown for $10 \mathrm{~d}$ on Plate Dextrose Agar. The spore count of the inoculum solution was performed using a hemocytometer. 
The experimental design was completely randomized with two treatments /Control: standardized size without superfine grinding and Treatment B: higher antioxidant). Six different dose concentrations of green propolis extract $(0,1,2,3,4$ and $5 \%)$ were tested. Five replicates were used for each evaluated dose, and the experimental unit was represented by a Petri plate 18.54 $\mathrm{cm})$. After inoculation, the plates were inverted and incubated under controlled conditions at $25^{\circ} \mathrm{C}$ with a $12 \mathrm{~h}$ photoperiod. The inhibition percentage of fungal growth from 1 to $5 \%$ dose were calculated in relation to the mycelial growth of zero dose (without extract) on the third day of incubation. The radial mycelial growth was measured using a digital caliper, and the diameter of each colony was measured in two directions that were perpendicular to each other. The final diameter of colony growth was the arithmetic mean of these two measurements. The inhibition of mycelial growth was given by PI $(\%)=$ (zero dose growth $/$ treatment growth $) \times 100$ (Alvarez-Castellanos et al., 2001).

The antifungal analysis was performed in a treatment that presented higher combined TPC, ABTS and DPPH scavenging values than the control.

\section{Statistical analysis}

The data reported were analyzed by one-way analysis of variance (ANOVA) at $p<0.05$ using Statistica v.12 software. The significance of differences between treatments were determined $(p<0.05)$ using the Tukey's range test. All data reported were expressed as the mean standard deviation from a minimum of two experiments conducted in triplicate. For the antifungal essay, the colony diameter $(\mathrm{cm})$ and growth inhibition data were adjusted using regression models, and the most appropriate model was the model with highest coefficient of determination $\left(\mathrm{R}^{2}\right)$.

\section{Results and Discussion}

\section{Particle size and mass percent determination by SEM/EDX}

Figures 1 and 2A-F show SEM/EDX micrographs obtained from samples before (control) and after the superfine grinding process, with the corresponding mass percent fractions (Table 1).
The SEM/EDX analysis showed that particles in the control treatment presented a size $>1 \mathrm{~mm}$ (Figure 1), and after the grinding process, the average particle size was $23.3 \mu \mathrm{m}$ for $\mathrm{A}, 21.3 \mu \mathrm{m}$ for $\mathrm{B}, 19.3$ $\mu \mathrm{m}$ for $\mathrm{C}, 26.3 \mu \mathrm{m}$ for $\mathrm{D}, 24.3 \mu \mathrm{m}$ for $\mathrm{E}_{\text {, }}$ and $24.0 \mu \mathrm{m}$ for $\mathrm{F}$ (Figure 2). Only particles with a defined morphology were measured. Rugged surfaces covered by layers of wax and extracts were observed in all SEM-EDX images. Similar characteristics were identified by Tylkowski et al. (2010) for Bulgarian propolis samples. Machado et al. (2016) observed some vegetable constituents and resinous substances derived from vegetative species of Baccharis dracunculifolia in propolis powders.

The images show that propolis ground with a $0.08 \mathrm{~mm}$ diameter sieve presented smaller and more uniform particles. The samples ground with a $0.5 \mathrm{~mm}$ diameter sieve presented larger particles, which was expected due to the different sieve diameter. Treatment $B$ produced particles that were more uniform than those produced by other treatments. The presence of wax in the propolis powders resulted in larger agglomerates of particles for all treatments. The particle sizes

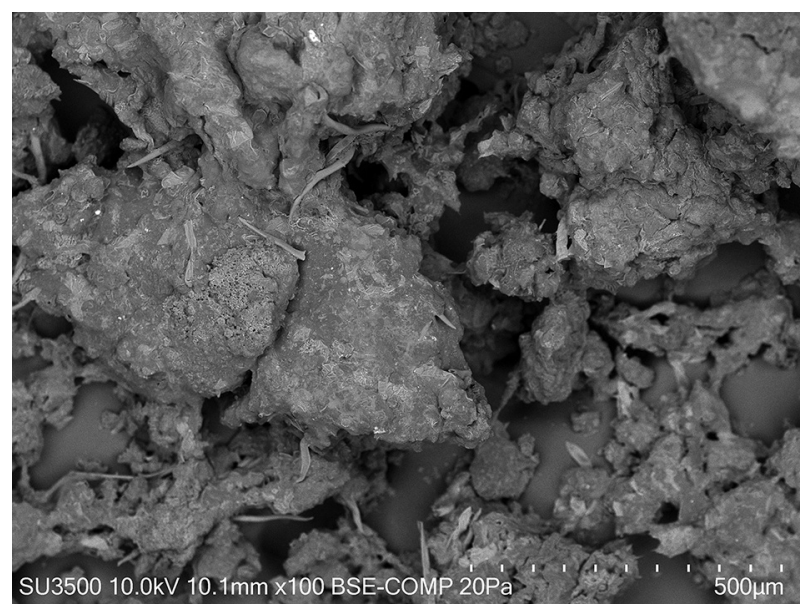

Figure 1 - Raw green propolis micrograph with a standardized particle size larger than $1 \mathrm{~mm}$ (control treatment) observed through scanning electron microscopy-energy dispersive X-ray spectroscopy.

Table 1 - Mass percent of carbon, nitrogen, oxygen and potassium fractions in green propolis powders after grinding.

\begin{tabular}{lcccc}
\hline \multirow{2}{*}{ Treatments } & \multicolumn{4}{c}{ Fractions (\% mass percent) } \\
\cline { 2 - 5 } & Carbon $^{*}$ & Nitrogen $^{*}$ & Oxygen $^{*}$ & Potassium $^{*}$ \\
\hline Control & $73.03 \pm 3.63 \mathrm{a}$ & $5.17 \pm 1.47 \mathrm{~b}$ & $20.77 \pm 1.59 \mathrm{a}$ & $0.95 \pm 0.42 \mathrm{a}$ \\
$\mathrm{A}$ & $75.36 \pm 3.00 \mathrm{a}$ & $3.54 \pm 0.36 \mathrm{a}$ & $21.17 \pm 1.55 \mathrm{a}$ & $0.80 \pm 0.43 \mathrm{a}$ \\
$\mathrm{B}$ & $75.26 \pm 0.87 \mathrm{a}$ & $3.22 \pm 0.00 \mathrm{a}$ & $21.66 \pm 1.90 \mathrm{a}$ & $1.52 \pm 1.32 \mathrm{a}$ \\
$\mathrm{C}$ & $74.40 \pm 1.11 \mathrm{a}$ & $3.34 \pm 0.17 \mathrm{a}$ & $22.34 \pm 2.44 \mathrm{a}$ & $0.98 \pm 0.21 \mathrm{a}$ \\
D & $76.72 \pm 5.38 \mathrm{a}$ & $4.27 \pm 0.00 \mathrm{~b}$ & $19.69 \pm 3.85 \mathrm{a}$ & $2.00 \pm 1.94 \mathrm{a}$ \\
E & $76.02 \pm 4.56 \mathrm{a}$ & $3.86 \pm 0.62 \mathrm{a}$ & $19.63 \pm 3.14 \mathrm{a}$ & $1.47 \pm 1.03 \mathrm{a}$ \\
F & $75.40 \pm 0.62 \mathrm{a}$ & $3.41 \pm 0.42 \mathrm{a}$ & $20.37 \pm 0.56 \mathrm{a}$ & $1.56 \pm 1.44 \mathrm{a}$ \\
\hline
\end{tabular}

${ }^{*}$ Means within the same column sharing the same letter are not significantly different at $p>0.05$. 

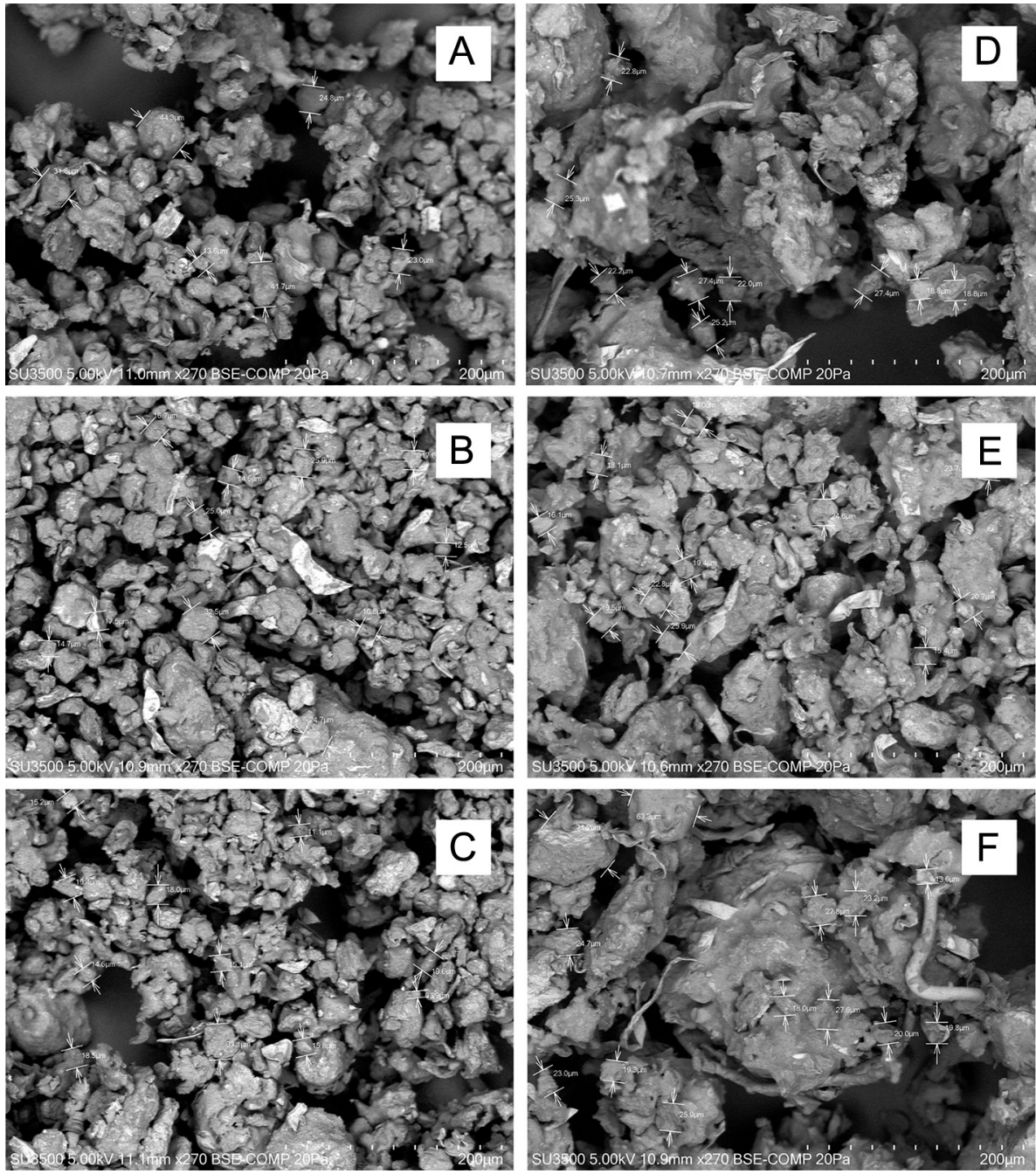

Figure 2 - Superfine ground (A) sieve $0.08 \mathrm{~mm} \varnothing$ at $6000 \mathrm{rpm}$; B) sieve $0.08 \mathrm{~mm} \varnothing$ at 12,000 rpm; C) sieve $0.08 \mathrm{~mm} \varnothing$ at $18,000 \mathrm{rpm}$; D) sieve $0.5 \mathrm{~mm} \varnothing$ at $6000 \mathrm{rpm}$; E) sieve $0.5 \mathrm{~mm} \varnothing$ at 12,000 rpm; and F) sieve $0.5 \mathrm{~mm} \varnothing$ at $18,000 \mathrm{rpm}$ ) green propolis micrographs observed through scanning electron microscopy-energy dispersive X-ray spectroscopy and magnified at $200 \mu \mathrm{m}$.

obtained were much smaller than those found by Ming et al. (2015), who obtained ground mushroom particles with sizes of 0.54 and $0.46 \mu \mathrm{m}$. Zhu et al. (2014) evaluated the effect of ultrafine grinding on wine grape pomace and obtained powders with particle sizes ranging from 0.38 to $29.91 \mu \mathrm{m}$.

In general, the soluble fraction of propolis has components with antioxidant properties and it has been

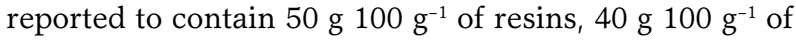

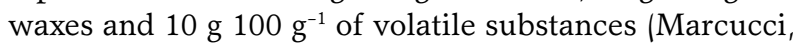
1995). Machado et al. (2016) found $90 \%$ of total solids, $3 \%$ of total ash, $10 \%$ of protein, $47 \%$ of lipids and 350 $\mathrm{mg}$ of potassium per kilogram of propolis in Brazilian green propolis. In terms of the mass percent quantified using SEM/EDX in the present study, the contents were unchanged after superfine grinding (Table 1) and the amounts found were consistent with those reported in the literature.

\section{TPC and antioxidant activity}

Table 2 shows TPC and antioxidant activity determined by the ABTS and DPPH scavenging assays. For particle sizes > $1 \mathrm{~mm}$, the TPC was $67.9 \mathrm{mg} \mathrm{GAE} \mathrm{g}^{-1}$ propolis, and after superfine grinding, the content increased, with values twice as high as the control treatment, ranging from 108.8 to $138.6 \mathrm{mg} \mathrm{GAE} \mathrm{g}^{-1}$ propolis.

Comparing TPC data with other studies, Mello and Hubinger (2012) found TPC values in green propolis that ranged from 49.80 to $100.59 \mathrm{mg} \mathrm{GAE} \mathrm{g}^{-1}$ propolis. In propolis samples from Bahia (Brazil), TPC values ranged from 22.03 to $39.38 \mathrm{mg} \mathrm{GAE} \mathrm{g}^{-1}$ propolis. Those values were lower than those found in the present study.

The antioxidant activity of extracts was evaluated using two different methods considering that antioxidants act via multiple mechanisms based on their mechanism of action, the tested radical source and oxidizing medium (Prior et al., 2005). Higher values were ob- 
Table 2 - Total Phenolic Content (TPC), ABTS [2,2'-azinobis-(3ethylbenzothiazoline-6-sulfonic acid)] and DPPH (2,2-diphenyl-1picrylhydrazyl) antioxidant activity of green propolis extracts.

\begin{tabular}{lccc}
\hline Treatment & \multicolumn{1}{c}{ TPC $^{*}$} & ABTS $^{2 *}$ & DPPH $^{2 *}$ \\
\hline Control & $67.9 \pm 2.7 \mathrm{a}$ & $1826.6 \pm 27.2 \mathrm{a}$ & $210.3 \pm 3.0 \mathrm{a}$ \\
$\mathrm{A}$ & $136.0 \pm 0.6 \mathrm{~d}$ & $8773.6 \pm 12.2 \mathrm{e}$ & $684.9 \pm 8.9 \mathrm{~b}$ \\
$\mathrm{~B}$ & $138.6 \pm 2.2 \mathrm{~d}$ & $8497.0 \pm 52.9 \mathrm{~d}$ & $781.2 \pm 3.0 \mathrm{C}$ \\
$\mathrm{C}$ & $137.7 \pm 1.3 \mathrm{~d}$ & $8491.5 \pm 21.2 \mathrm{~d}$ & $682.8 \pm 11.1 \mathrm{~b}$ \\
$\mathrm{D}$ & $108.8 \pm 1.6 \mathrm{~b}$ & $8240.1 \pm 84.7 \mathrm{~b}$ & $686.1 \pm 9.2 \mathrm{~b}$ \\
$\mathrm{E}$ & $135.2 \pm 1.2 \mathrm{~d}$ & $8052.0 \pm 84.7 \mathrm{~b}$ & $761.5 \pm 9.9 \mathrm{c}$ \\
$\mathrm{F}$ & $130.4 \pm 1.0 \mathrm{c}$ & $8300.3 \pm 63.5 \mathrm{C}$ & $758.9 \pm 4.7 \mathrm{c}$ \\
\hline${ }^{1} \mathrm{mg}$ of gallic acid equivalent $\mathrm{g}^{-1}$ of propolis; ${ }^{2} \mu \mathrm{mol}$ Trolox-equivalent antioxidant \\
capacity $\mathrm{g}^{-1}$ of propolis; ${ }^{*}$ Means within the same column sharing the same \\
letter are not significantly different at $p>0.05$.
\end{tabular}

served in the ABTS assay for smaller sieve sizes (8491.5 to $8773.6 \mu \mathrm{mol} \mathrm{TEAC} \mathrm{g}{ }^{-1}$ propolis) (Table 2). Palomino et al. (2009) evaluated the propolis activity from Colombia and obtained results ranging from 455.5 to $1091 \mu \mathrm{mol}$ TEAC $\mathrm{g}^{-1}$ propolis, which are lower than the values found in the present study.

In the DPPH method, the free radical DPPH reacts with antioxidant compounds in extracts, mainly phenolic groups. As observed in the ABTS results, the higher values were observed for the treatments with smaller sieve diameters. The DPPH assay values range to 682.8 from $781.2 \mu \mathrm{mol} \mathrm{TEAC} \mathrm{g}{ }^{-1}$ propolis (Table 2). Treatment $\mathrm{B}$ presented the highest TPC and DPPH values among tested treatments, and this could be related to the fact that treatment $\mathrm{B}$ particles showed the most uniform morphology.

As observed and reported in other studies, particle size of samples is an important parameter that influences extraction yield because smaller particle sizes increase extraction surface and enhance extraction efficiency (Gião et al., 2009). Interactions between solute and solvent increase when the size of extraction material decreases; consequently, more antioxidant compounds can be extracted from smaller particles, resulting in an extract with a higher antioxidant activity (Chan et al., 2012). The relationship between smaller particle size and higher TPC and antioxidant activity has been observed in other studies (Aboshora, 2016; Chan et al., 2012; Marcucci, 1995).

\section{Antifungal activity}

Rhizopus stolonifer is an important postharvest disease agent in strawberries, resulting in soft rot (Alvarez-Castellanos et al., 2001). As reported above, for the antifungal essay, only the control and $\mathrm{B}$ treatments were tested. According to the results, both green propolis extracts presented antifungal activity against $R$. stolonifer, and the activity was dose-dependent (Figure 3). After three days of incubation, the control treatment extract showed greater action on the pathogen because its lower concentration was able to inhibit mycelial growth by more than $90 \%$, and total inhibition was observed

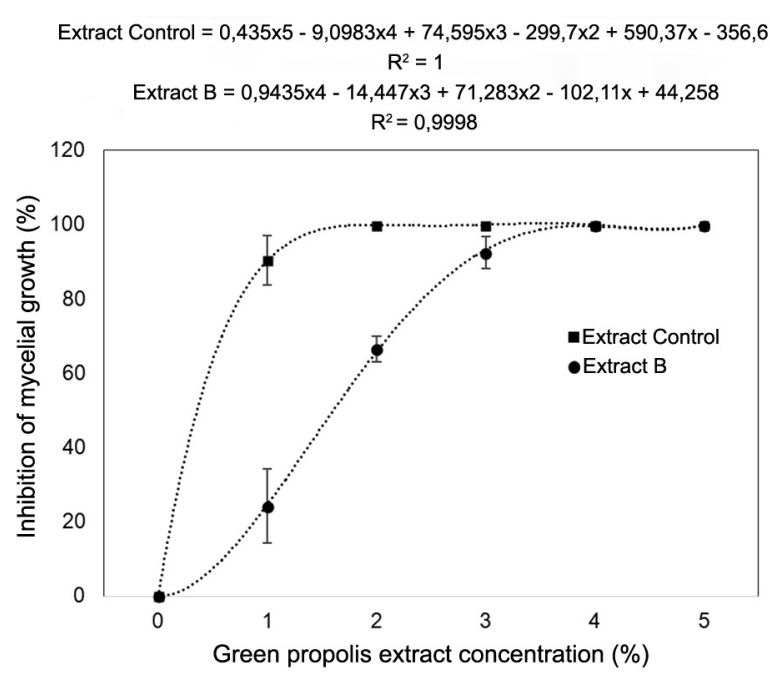

Figure 3 - Inhibition of exposed Rhizopus stolonifer mycelial growth (\%) via agar contact with different concentrations of green propolis extracts after three days of incubation. Vertical bars represent the standard deviation of five replicates.

at a $2 \%$ concentration. Both extracts showed potential antifungal activity with increasing concentration. Treatment B inhibited $R$. stolonifer mycelial growth totally at a $4 \%$ concentration. Therefore, the results showed that the antifungal activity did not correlate with TPC or antioxidant activity.

The green propolis extracts, regardless of grinding type, presented antifungal activities against $R$. stolonifer. However, the control treatment, which had the lowest TPC, showed a greater effectiveness for the inhibition of mycelial growth of $R$. stolonifer at the lowest dose $(1 \%)$. The substances responsible for the beneficial biological activities of propolis, that is, its antimicrobial and antioxidant activities, are flavonoids and other phenolics, substituted cinnamic acids and their esters, caffeic acid phenethyl ester, kaempferol and quercetin (Freires et al., 2016; Martini et al., 2017; Ristivojević et al., 2015), which act in isolation or synergistically. However, according to Falcão et al. (2014), the observed bioactivity cannot be judged solely using TPC because some individual phenolic compounds in the extract may play a more important role in the activity than others. According to some authors, the action mechanism observed is due to the deactivation of enzymes in microbial metabolism because of the hydrogen bonds that hydroxyl groups in phenolic compounds can form with microbial enzymes (Juglal et al., 2002; Porte and Godoy, 2001).

Falcão et al. (2014) observed that the antifungal activity of propolis and plant extracts may not be related to the total antioxidant content, but to the composition of the phenolic compounds fraction, instead. In addition, the antioxidant activity cannot be related to the antifungal efficiency because the antimicrobial activity is mainly related to nonpolar compounds and the antioxidant activity to polar compounds (Adamu et al., 2014). 


\section{Conclusions}

The superfine grinding method can effectively reduce particle size of Brazilian green propolis powders and change the original surface structure, improving their solvent extraction characteristics. After superfine grinding, the mean particle size decreased. No change was observed in the mass percentage of propolis constituents (carbon, nitrogen, oxygen and potassium), and increased antioxidant activity was observed. The antifungal data indicates that Brazilian green propolis extract has the potential to be applied as a natural antifungal agent against $R$. stolonifer.

The application of the ultrafine powders depends on their chemical composition, physical properties, and the superfine grinding method. Therefore, superfineground Brazilian green propolis powders could be used in several fields, for example, as a food preservative to improve shelf life by inhibiting oxidation and fungal growth.

\section{Acknowledgements}

The authors are grateful for the support provided by Universidad de La Frontera/Fundação de Amparo à Pesquisa do Estado de São Paulo (UFRO/FAPESP) (Grant no. 2014/50235-7), FAPESP (Project no. 2014/18227-4), Coordenação de Aperfeiçoamento de Pessoal de Nivel Superior (CAPES) for the scholarship granted and Natucentro Propolis ${ }^{\circledR}$ for providing samples.

\section{Authors' Contributions}

Conceptualization: Augusto-Obara, T.R.; Vieira, T.M.F.S.; Scheuermann, E. Data acquisition: AugustoObara, T.R.; de Oliveira, J.; da Gloria, E.M.; Godoy, K. Data analysis: Augusto-Obara, T.R.; de Oliveira, J.; da Gloria, E.M.; Godoy, K.; Spoto, M.H.F.; Vieira, T.M.F.S.; Scheuermann, E. Design of methodology: Augusto-Obara, T.R.; Spoto, M.H.F.; Vieira, T.M.F.S.; Scheuermann, E. Writing and editing: Augusto-Obara, T.R.; Spoto, M.H.F.; Vieira, T.M.F.S.; Scheuermann, E.

\section{References}

Aboshora, W. 2016. Functional foods: effect of superfine grinding on functional properties and antioxidant capacities of dietary fiber from cereal bran, fruits and vegetables. Bioaccent Online Publishing Nutrition 2: 9-10.

Adamu, M.; Naidoo, V.; Eloff, J.N. 2014. The antibacterial activity, antioxidant activity and selectivity index of leaf extracts of thirteen South African trees species used in ethnoveterinary medicine to treat helminth infections. BMC Veterinary Research 10: 1-7.

Alencar, S.M.; Aguiar, C.L.; Paredes-Guzmán, J.; Park, Y.K. 2005. Chemical composition of Baccharis dracunlifolia, the botanical source of propolis from the states of São Paulo and Minas Gerais, Brazil. Ciência Rural 35: 909-915 (in Portuguese, with abstract in English).
Alvarez-Castellanos, P.P.; Bishop, C.D.; Pascual-Villalobos, M.J. 2001. Antifungal activity of the essential oil of flower heads of gargland chrysanthemum (Chrysanthemum coronarium) against agricultural pathogens. Phytochemistry 57: 99-102.

Brand-Williams, W.; Cuvelier, M.E.; Berset, C. 1995. Use of a free radical method to evaluate antioxidant activity. Food Science and Technology 28: 25-30.

Bruschi, M.L.; Pereira, R.R.A.; Francisco, L.M. 2016. The use of propolis in micro/nanostructured pharmaceutical formulations. Recent Patents on Drug Delivery \& Formulation 10: $130-140$.

Cacaeo, J.E.; Mazza, G. 2003. Mass transfer process during extraction of phenolic compounds from milled berries. Journal of Food Engineering 59: 379-389.

Chan, E.W.C.; Lye, P.Y.; Tan, L.N.; Eng, S.Y.; Tan, Y.P.; Wong, Z.C. 2012. Effects of drying method and particles sizes on the antioxidant properties of leaves and teas of Morus alba, Lagerstroemia speciosa and Thunbergia laurifolia. Chemical Industry \& Chemical Engineering Quarterly 18: 465-472.

Chinembiri, T.N.; Plessis, L.H.; Gerber, M.; Hamman, J.H.; Plessis, J. 2014. Review of natural compounds for potential skin cancer treatment. Molecules 19: 11679-11721.

Cottica, S.M.; Sabik, H.; Bélanger, D.; Giroux, H.J.; Visentainer, J.V.; Britten, M. 2015. Use of propolis extracts as antioxidant in dairy beverages enriched with conjugated linoleic acid. European Food Research and Technology 241: 543-551.

Falcão, S.I.; Vale, N.; Cos, P.; Gomes, P.; Freire, C.; Maes, L.; Vilas-Boas, M. 2014. In vitro evaluation of Portuguese propolis and floral sources for antiprotozoal, antibacterial and antifungal activity. Phytoterapy Research 28: 437-443.

Fernandes-Silva, C.C.; Salatino, M.L.F.; Teixeira, E.W.; Salatino, A. 2014. Analysis of the volatile fraction of a Brazilian propolis from Ubatuba (SP) shows unusual chemical composition and anti-HIV properties. Planta Medica 80: 1514-1514.

Franco, D.; Pinelo, M.; Sineiro, J.; Nunez, M.J. 2007. Processing of Rosa rubiginosa: extraction of oil and antioxidant substances. Bioresources Technology 98: 3506-3512.

Freires, I.A.; Queiroz, V.C.P.P.; Furletti, V.F.; Ikegaki, M.; Alencar, S.M.; Duarte, M.C.T.; Rosalen, P.L. 2016. Chemical composition and antifungal potential of Brazilian propolis against Candida spp. Journal de Mycologie Médicale 26: 122132 .

Gião, M.S.; Pereira, C.P.; Fonseca, S.C.; Pintado, M.E.; Malcata, F.X. 2009. Effect of particle size upon the extent of extraction of antioxidant power from the plants Agrimonia eupatoria, Salvia sp. and Satureja montana. Food Chemistry 117: 412416.

Guimarães, N.S.S.; Mello, J.C.; Paiva, J.S.; Bueno, P.C.P.; Berretta, A.A.; Torquato, R.J.; Nantes, I.L.; Rodrigues, T. 2012. Baccharis dracunlifolia, the main source of green propolis, exhibits potent antioxidant activity and percent oxidative mitochondrial damage. Food Chemistry and Toxicology 50: 1091-1097.

Juglal, S.; Govinden, R.; Odhav, B. 2002. Spice oils for the control of co-occurring micotoxin-producing fungi. Journal of Food Protection 65: 683-687. 
Machado, B.A.S.; Silva, R.P.D.; Barreto, G.A.; Costa, S.S.; Silva, D.F.; Brandão, H.N.; Rocha, J.L.C.; Dellagostin, O.A.; Henriques, J.A.P.; Umsza-Guez, M.A.; Padilha, F.F. 2016. Chemical composition and biological activity of extracts obtained by supercritical extraction and ethanolic extraction of brown, green and red propolis derived from different geographic regions in Brazil. PloS One 11: e0145954.

Marcucci, M.C. 1995. Propolis: chemical composition, biological properties and therapeutic activity. Apidologie 26: 83-99.

Martini, D.; Barbosa, G.F.; Matias, R.; Filho, W.C.M.; Garcia, N.Z.T. 2017. Seasonality on the antifungal potential of green propolis collected in Campo Grande - MS, Brazil. Ciência Rural 47: 1-6.

Mello, B.C.B.S.; Hubinger, M.D. 2012. Antioxidant activity and polyphenol contents in Brazilian green propolis extracts prepared with the use of ethanol and water as solvents in different $\mathrm{pH}$ values. International Journal of Food Science and Technology 47: 2510-2518.

Ming, J.; Chen, L.; Hong, H.; Li, J. 2015. Effect of superfine grinding on the physico-chemical, morphological and thermogravimetric properties of Lentinus edodes mushroom powders. Journal of the Science of Food and Agriculture 95: 2431-2437.

Ngatu, N.R.; Saruta, T.; Hirota, R.; Eitoku, M.; Muzembo, B.A.; Matsui, T.; Nangana, L.S.; Mbenza, M.A.; Kumagai, N.; Suganuma, N. 2011. Antifungal efficacy of Brazilian green propolis extracts and honey on Tinea capitis and Tinea versicolor. European Journal of Integrative Medicine 3: 281-287.

Osés, S.M.; Pascual-Maté, A.; Fernández-Muiño, M.A.; LópezDíaz, T.M.; Sancho, M.T. 2016. Bioactive properties of honey with propolis. Food Chemistry 196: 1215-1223.

Palomino, L.R.G.; Garcia, C.M.P.; Gil, J.H.G.; Rojano, B.A.; Durango, D.L.R. 2009. Determination of phenolic content and evaluation of antioxidante activity of propolis from Antioquia (Colombia). Vitae 16: 388-395 (in Spanish, with abstract in English).

Porte, A.; Godoy, R.L.O. 2001. Rosemary (Rosmarinus officinallis L.): essential oil antimicrobial and chemical properties. Boletim Centro de Pesquisa de Processamento de Alimentos 19: 193210 (in Portuguese, with abstract in English).

Prior, R.L.; Wu, X.; Schaich, K. 2005. Standardized methods for the determination of antioxidant capacity and phenolics in foods and dietary supplements. Journal of Agricultural and Food Chemistry 53: 4290- 4302.
Re, R.; Pellegrini, N.; Proteggente, A.; Pannala, A.; Yang, M.; RiceEvans, C. 1999. Antioxidant activity an improved ABTS radical cation decolorization assay. Free Radical Biology \& Medicine 26: 1231-1237.

Ribeiro, M.R.G.; Gualberto, A.M.; Silva, M.A.S.; Souza, S.F.C.; Souza, E.M.; Silva, V.C. 2015. Results of topical application of propolis extracts in reducing progression of periodontal disease. Revista Brasileira de Plantas Medicinais 17: 915-921 (in Portuguese, with abstract in English).

Ristivojević, P.; Trifkovic, J.; Gasic, U.; Andric, F.; Nedic, N.; Tesic, Z.; Milojkovic-Opsenica, D. 2015. Ultrahigh-performance liquid chromatography and mass spectrometry (UHPLC-LTQ/ Orbitrap/MS/MS) study of phenolic profile of Serbian poplar type propolis. Phytochemical Analysis 26: 127-136.

Rosa, N.N.; Barron, C.; Gauanni, C.; Dufour, C.; Micard, V. 2013. Ultra-fine grinding increases the antioxidant capacity of wheat bran. Journal of Cereal Science 57: 84-90.

Singleton, V.L.; Orthofer, R.; Lamuela, R.M. 1999. Analysis of total phenols and other oxidation substrates and antioxidants by means of Folin-Ciocalteau reagent. Methods in Enzymology 299: 152-178.

Tylkowski, B.; Trusheva, B.; Bankova, V.; Giamberini, M.; Peev, G.; Nikolova, A. 2010. Extraction of biologically active compounds from propolis and concentration of extract by nanofiltration. Journal of Membrane Science 348: 124-130.

Vilgalys, R.; Hester, M. 1990. Rapid genetic identification and mapping of enzymatically amplified ribosomal DNA from several Cryptococcus species. Journal of Bacteriology 172: 42394246.

Viuda-Martos, M.; Ruiz-Navajas, Y.; Fernández-López, J.; PérezÁlvarez, J.A. 2008. Functional properties of honey, propolis, and royal jelly. Journal of Food Science 73: R117-R124.

Wang, K.; Jin, X.; Chen, Y.; Song, Z.; Jiang, X.; Hu, F.; Conlon, M.A.; Topping, D.L. 2016. Polyphenol-rich propolis extracts strengthen intestinal barrier function by activating AMPK and ERK signaling. Nutrients 8: 272-283.

Wu, G.C.; Zhang, M.; Wang, Y.Q.; Mothibe, K.J.; Chen, W.X. 2012. Production of silver carp bone powder using superfine grinding technology: suitable production parameters and its properties. Journal of Food Engineering 109: 730-735.

Zhu, F.M.; Du, B.; Li, J. 2014. Effect of ultrafine grinding on physicochemical and antioxidant properties of dietary fiber from wine grape pomace. Food Science and Technology International 20: 55-62. 